\title{
Communication and public participation processes in the sustainable tourism planning of the first capital of the Californias
}

\author{
M. Arizpe, O. Arizpe \& A. Gamez \\ University of Baja California Sur, Mexico
}

\begin{abstract}
The successful management of coastal zones and the activities that occur in them, especially in the case of Protected Natural Areas (NPAs), requires the integration of the communities that live in those areas and their participation in those activities. It is important to incorporate environmental education, schemes for information diffusion and good communication in the management plans. In the Gulf of California region, environmental information diffusion directed towards the community is merely informative, it does not consider the surroundings and necessities of the local population, and is not structured from an interdisciplinary approach. In this context, the main objective of this study was to develop a public participation strategy, involving good communication and the input of local people. This strategy could be incorporated into sustainable tourism management plans. With this approach, the processes of environmental communication and Ecological Ordering in the region of Loreto were evaluated. The results of meetings summoned by the tourist planning groups of the region were analyzed, as were the results of surveys and interviews aimed at the local inhabitants. A strategy, incorporating effective communication and community involvement, was devised which could be used in future tourism planning processes.
\end{abstract}

Keywords: communication, public participation, community involvement, ecological ordering, environmental management, tourism, Loreto.

\section{Introduction}

When developing activities such as sustainable tourism in Natural Protected Areas (NPAs) of costal zones, it is important to consider and involve the human 
communities that live in and interact with them (Fraser [1]). However, it is only in recent years that the concept of environmental investigation has been extended to include human social aspects such as necessities, attitudes and environmental knowledge of resident populations. To incorporate these social aspects, diffusion of environmental information and good communication is imperative when formulating programs of environmental management and it must stimulate the participation of the community in the process of sustainable development.

\subsection{Ecological ordering of territory}

In Mexico, Ecological Ordering of Territory is the instrument of environmental policy that evaluates the characteristics of a certain area and that induces or regulates the use of land and productive activities within it. In this study, it serves to illustrate how a lack of communication strategies makes community integration difficult in enviromental programs such as sustainable tourism development.

The Objective of Ecological Ordering is preservation of the environment, while considering social and economic aspects such as rational use of natural resources. It also aims at sustainability of productive activities, which in the case of the Gulf of California could be exemplified by sustainable tourism. This should allow balanced, long-term development in popular tourist destinations and promote regional development and benefits to local communities (SEMARNAT-INE [2]).

The participation of local leaders in the process of Ordering is indispensable, because it grants legitimacy and facilitates the application of all processes of environmental management and development of productive activities. Their participation also acknowledges the importance of the point of view of local communities and ensures feedback for future decisions.

This study was focused in the coastal and marine zone of Loreto, BCS (Mexico). The city of Loreto, well-known as the First Capital of the Californias, was founded in 1697. It became a municipality in 1992, with an area of 4.878 $\mathrm{km} 2$ The area of this study is located in the capital City of the Loreto. Today it has 15000 inhabitants, and through time it has been under very diverse development plans, without having obtained the desired results so far. A number of ecosytemic studies of vocation and land use impact carried between 1982 and 1983 , concluded that the integrated vocation of the area is that of conservation, recreation and tourism. In addition, The National Institute of Ecology elaborated Ecological Ordering of the region in 1995, determining that the coastal zone of Loreto has a tourism and recreational vocation.

It is necessary to incorporate the perspective of environmental communication to achieve the basic schemes of diffusion in the management plans. In the Gulf of California region, the attempts at environmental diffusion directed towards the community have been merely informative, they have not considered the surroundings, reality and necessities of the local population, and are not structured from an interdisciplinary point of view. 


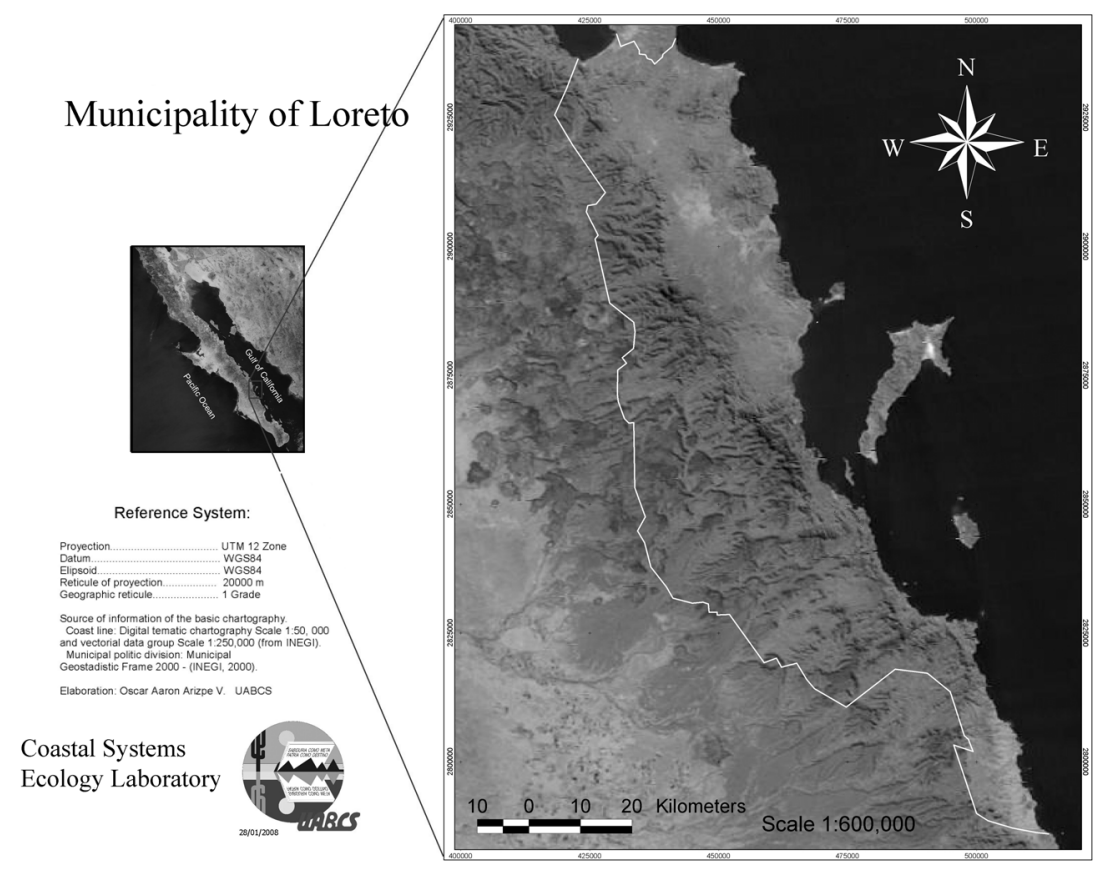

Figure 1: $\quad$ Location of the study area.

The principal objective of this work is to develop a public participation strategy that involves good communication and public participation, with the final purpose of integrating it into the Tourism Management Plan of the coastal and marine zone of the Loreto region.

\section{Methods}

In order to analyze the effectiveness of communication processes and community involvement in the coastal and marine zone of Loreto, from the perspective of the Ecological Ordering, meetings were summoned by the Secretaria del Medio Ambiente y Recursos Naturales - Enviroment and Natural Resources Secretary - (SEMARNAT) at state level and by the government of the municipality of Loreto between July 2005 and May 2007. These meetings tried to collect the points of view of the three levels of government and those of civil organizations and people related to SEMARNAT. As a complement, surveys were raised in three central points of the city of Loreto during December 2006, collecting information from 79 people aged between 18 and 56, with the objective of analyzing the degree of diffusionof information of these programs. Some of the participants mentioned people within the community as "informed on the subject". It was tried interview as many of these individuals as possible. 
The viewpoint was further widened by incorporating the results obtained through the surveys applied by Carrillio and Ganster [3], to study Alternative Futures for the Region of Loreto The qualitative indicators were based on the survey in Loreto. The quantitative indicators were then developed through a revision of official data for Loreto and the region. The criteria for the selection of these indicators includes these factors: the degree of trust of the source, reasonable methodology used to collect to the data, and the continued production of data. The qualitative data that were obtained for the Alternative Futures was generated through a directed investigation in Loreto by investigators of the SDSU and UABCS in March of 2004. Seventy seven people selected at random from eleven zones in Loreto and Nopoló participated in the survey. The total population of the urban area was 10,015, giving a margin of error of $+/$ $11.1 \%$ with a level of confidence of $95 \%$.

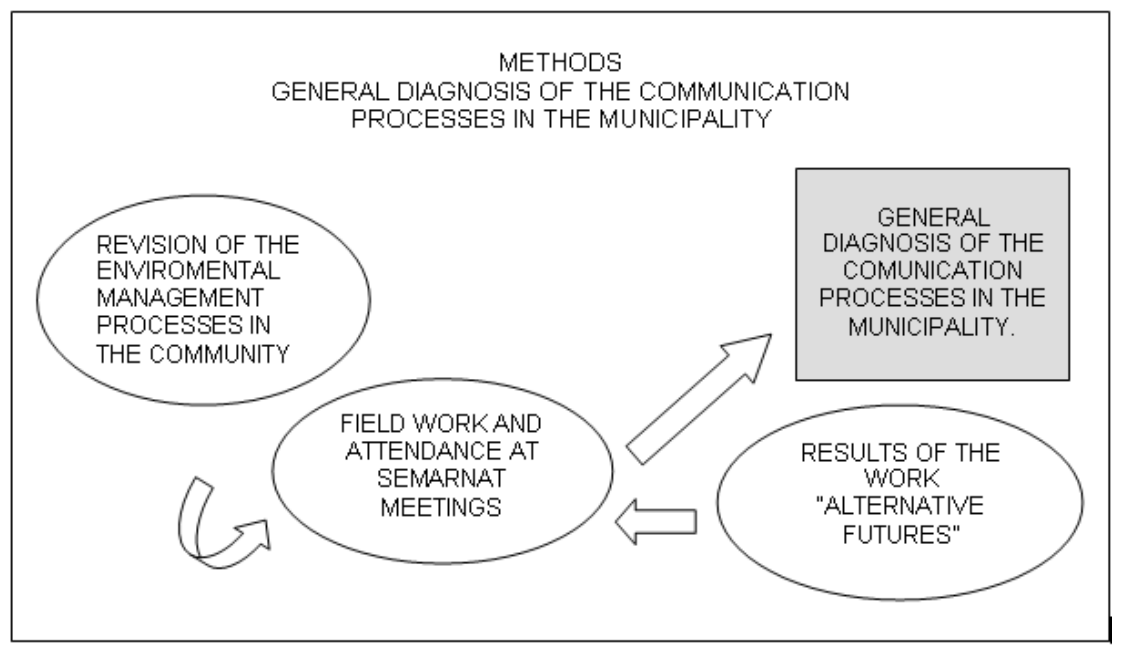

Figure 2: General diagnosis of the communication processes in the municipality.

\section{Results}

Although Loreto has been the object of the elaboration of different programs of Ecological Ordering, the local community has ignored the existence of the great majority of these programs and processes. While it is true that not one of these programs has been published or implemented, not one of these programs has included any strategies of diffusion and public participation. The interest by part of the population and different sectors from the community has been manifested on various occasions. In fact, between 1992 and 1994, by means of letters and formal requests directed to the Federal Executive, the community as a whole has showed its concern over pollution and enviromental degradation found in the area of the Bay of Loreto (CONANP [4]). 
In this particular case, the social pressure was answered when the Municipal Council of Enviroment was created by the municipal government. On the 19th of July1996, the zone denominated Bahia de Loreto was declared an NPA.

\subsection{Public participation and diffusion from the point of view of Loreto inhabitants}

Several factors that helped to establish the level of participation and interest of the community of Loreto were identified from the analysis of the investigation of SDSU, based on interviews and informal conversations with the residents of the region of Loreto. The vast majority of people (86\%) in Loreto report that they were satisfied with the quality of life in their community Carrillio and Ganster [3]. They also had a strong sense of the historical past. All of this was reflected in their high levels of public participation. The community also showed a quite significant internal cohesion. The Loretans, as a whole, felt satisfied with their city, their community, the region and the enviroment in its present state, and maintained a positive vision for the future Steinitz et al. [5]. This served to identify the degree of knowledge of the community regarding the existence of proposals of Ecological Ordering which already existed for the region. A high level of participation was observed during the study. Only two people declined to participate in the survey, and most people openly discussed the subjects that worried them the most. Among the main preoccupations of the population of Loreto are the lack of water, the excessive development that could occur in a future, and the loss or deterioration of the landscape.

One of the most important points is that despite the great interest and clear vision shown by the majority of the population, a great number of the participants (89\%) (including several members of local Civil Organizations), did not have knowledge of the programs of enviromental management in Loreto. No program of Ecological Ordering in Loreto to date has tried to include the community in its formulation and integration, nor have they included strategies of participation or diffusion for this purpose. Even at state level, SEMARNAT [6], has clarified that there is no strategy to approach the Ecological Ordering program and its processes to the population. It also lacks a committee or department of social communication or public relations, and any personnel specialized in this area. This could explain why there are no financial or human resources contemplated for the diffusion and stimulus of public participation.

\subsection{Communication and community involvement strategy, designed to be included in the environmental management processes linked to sustainable tourism}

It is necessary to incorporate the society in the construction of the instruments of environmental management, with the purpose of generating management schemes in which a social perspective is included. Nevertheless, the principles of interdisciplinary participation are rarely taken into consideration within these processes. This is understandable considering the deficiencies of the past 
Ecological Ordering Programs. It is not enough just to elaborate a communication strategy. Communication needs to be viewed as a strategy in itself, in order to fulfill the objectives of any program of environmental management. From the findings of this paper, the following is recommended:

A. The creation of a commitee formed by people of different social areas, including, but not limited to: communication, law, and economy. This personnel must have knowledge of environmentally related topics. In this way, information formulated by the committee should be understood at all levels by the population, including governmental and economic ones.

B. Reconstruct the environmental communication campaigns to make them more accessible to the community as a whole. In order to achive this, it is important to evaluate the preferences and preoccupations concerning the environment and quality of life in the community, and to adapt the campaigns according to these results. This should persuade the community to adopting the strategies proposed by the program.

C. Use of the local media. The messages concerning the campaign should be short, clear, simple, strongly point out the benefits to the local communities and be constantly repeated. A real access to information about the program, and its would prove valuable too.

D. The campaign will be more effective when the community gains, financially or otherwise, from the institutions that propose it. Any actions must be fundamental and presented logically.

E. It is necessary to find the natural leaders of the community. These leaders can become a strong link between the authorities and the population, and their inclusion in the program facilitates its success and feedback.

F. The creation of public participation workshops has the advantage of allowing strong, periodic feedback and is a way to measure the advance of the program from the point of view of the community.

G. In these workshops it must be constantly reaffirmed that, in spite of all the participation, there will be obstacles to overcome and some objectives that will only be fulfilled in the long term. Likewise, they permit continuous dissemination of information about advances and targets reached.

H. It is extremely important that one of the fundamental long term objectives of this, and any environmental program, is that the community can define its own objectives and their own vision of the sustainability, can establish its internal and external communication networks, thus facilitating diffusion of information and participation in the long term.

\section{Discussion}

The processes of communication and public participation are fundamental to promote the involvement of the community in this sustainable tourism program and in enviromental programs in general. Important indicators of involvement and participation were detected within the local population of Loreto. The Strategy presented is directed towards this type of locality, as it tries to take advantage of community interest to encourage participation in the program of environmental management, here focussed on sustainable tourism. 
Well developed communication wthin enviromental management programs is key to their success (González-Gaudiano [7]). It must bestressed that the way a community understands a problem is different to the way an academic understands it. For the citizen, the industralist or the political authority, an environmental subject is important if it can help to achieve its immediate goals (Oepen [8]). A clear concern for the environmental is already evident within the population of Loreto (Steinitz et al. [5]). Their main environmental worries have been expressed on several occasions and through different means.

Locating community leadersis important, because very often it is they that focus the people's ideas about a certain situation. Knowing the point of view of the people, makes it clear what is expected by them of the program in the community.

The community should be advised of potential obstacles and difficulties to be resolved. This should maintain confidence and support towards the campaign if problems arise To communicate advances of the program boosts confidence and will to participate in it. It is important that the community defines its own objectives and visions. Thus, in the long term, it itself will look for contact with the institutions, establish its own perspective, participation and objectives regarding the sustainble activities that take place in its vicinity.

\section{References}

[1] Fraser, C. Communicating for development: human change for survival. I.B. Taurus Publishers, New York. 167 pp. 1998

[2] SEMARNAT-INE. Ordenamiento. http://www.ine.gob.mx 2001

[3] Carrillio, T. \& Ganster, P. "Quality of Life in Loreto: Challenges and Opportunities". In Loreto: The Future of the first capital of the Californias. P. Ganster, O. Arizpe, A. Ivanova, eds. San Diego: San Diego State University Press \& Institute for Regional Studies of the Californias. 2007

[4] CONANP. Bahía de Loreto. http://www.conanp.gob.mx 2006

[5] Steinitz, C. Alternative Futures for the Loreo Region, Baja California Sur, México, Harvard, SDSU, University of Arizona, CIBNOR, UABCS. Available in http://www.futurosalternativosloreto.org/report/es/index.htm In Press. 2007.

[6] SEMARNAT, Gutierrez L., Personal Communication. Head of Public Politics 4 April 2006, La Paz, Mexico.

[7] González-Gaudiano, E. Communication and Environmental Conflicts in México. In "Educación para la Conservación", Universidad Nacional Autónoma de México. México, DF. 135-150 pp. 2006

[8] Oepen, M. Communicating the environment. Environmental education, communication and sustainability. Edit. Peter Lang. Frankfurt. 96 pp. 2000 